\title{
USO Y SIGNIFICADO DE LOS OBJETOS EN LA LITERATURA FRANCESA SURREALISTA
}

\author{
USE AND MEANING OF OBJECTS IN FRENCH \\ SURREALIST LITERATURE
}

Jordi LUENGO LÓPEZ
Universidad Pablo de Olavide de Sevilla
luengo.jordi@gmail.com

\begin{abstract}
Resumen: El uso que en los textos surrealistas se le da a los objetos, constituye una de las bases de comunicación del pensamiento onírico de esta corriente artística, cuyo significante se reconoce en el particular modo de ver el mundo que tuvieron algunos escritores franceses. Centrándonos en la obra de André Breton y Louis Aragon se abordará este fenómeno a través del análisis del proceso de cristalización del objeto psíquico en el plano físico del texto escrito, no solo como elemento constituyente de la narración, sino también como objeto en sí al concebirse como poema-objeto o identificarse con el propio surrealismo.
\end{abstract}

Abstract: The use of objects in surrealist texts is one of the bases for communicating oneiric thought in this artistic movement, the meaning of which is recognised in the particular way that some French writers had of seeing the world. Focusing on the work of André Breton and Louis Aragon, 
this phenomenon is approached through an analysis of the process in which the psychological object is crystallised in the physical level of the written text, not only as an component of the narrative, but also as an object in its own right, in the way it is conceived as a poem-object or identified with surrealism itself.

Palabras clave: Objeto surrealista. Poema-objeto. André Breton. Louis Aragon.

Key words: Surrealist object. Poem-object. André Breton. Louis Aragon.

Tu m'as trouvé comme un caillou que l'on ramasse sur la plage Comme un bizarre objet perdu dont nul ne peut dire l'usage.

Louis Aragon

\section{APROXIMACIÓN AL OBJETO SURREALISTA}

Para comprender mejor el universo del objeto surrealista, y saber interpretar la simbología que sus formas encierra, antes que nada, debe conocerse a quienes concibieron inicialmente el objeto cotidiano como objeto de arte en sí: los dadás. Marcel Duchamp (1887-1968) fue el primero que, apartándose de su afición por la pintura, elevó a la categoría artística ciertos objetos propios de la vida cotidiana: Roue de bicyclette (1913), Porte bouteilles (1914) o Fontaine (1917), su famoso orinal invertido. Todos estos objetos, que, como apuntaban los dadás, ya existían, solo por el hecho de estar firmados por un artista - en ocasiones incluso con una firma inventa$\mathrm{da}^{1}$ - adquirían una dimensión distinta a la del resto de obras artísticas. Ahora bien, si para los dadaístas este gesto de otorgar categorías estéticas a los objetos ordinarios podía ser interpretado como una tentativa de ridiculizar el arte tradicional, en el caso de los surrealistas, esta iniciativa tenía como objetivo explorar todas las posibilidades que cualquier objeto banal pudiera ofrecer. Para conseguirlo, los surrealistas dotaron a los objetos de

${ }^{1}$ Duchamp, en La Fontaine, su célebre orinal invertido, firmó con el nombre de «R. Mutt». La «R» aludía a «Richard», cuyo significado era «rico» en argot francés, aunque Gloria Moure sugiere el juego de palabras «rich art» o «art rich»; mientras que el apellido «Mutt», según apunta George Bauer, era una alteración del término «Mott», nombre de los sanitarios de la sociedad J. L. Mott Iron Works, pese a que también se ha apuntado que el vocablo provenía del popular cómic Mutt and Jeff de Bud Fisher (1885-1954), cuyos protagonistas se caracterizaban por ser el primero muy bajo y el otro considerablemente alto (Ball, Knafo, 1990: 74-75; Foster, Krauss, Bois, 2006: 129). 
cierta dimensión estética, atribuyéndoles, al mismo tiempo, un sentido de la belleza estrechamente vinculado al de la sorpresa.

Será André Breton (1896-1966) quien propondrá la revitalización del objeto en sí. Como él mismo cuenta, fue un sueño lo que le inspiró la fabricación de objetos oníricos, siendo estos, por lo tanto, creados en el seno del subconsciente. En su ensayo Introduction au discours sur le peu de réalité (1924), Breton describe dicho sueño del siguiente modo:

[...] une de ces dernières nuits, dans le sommeil, à un marché en plein air qui se tenait du côté de Saint-Malo, j'avais mis la main sur un livre assez curieux. Le dos de ce livre était constitué par un gnome de bois dont la barbe blanche, taillée à l'assyrienne, descendait jusqu'aux pieds. L'épaisseur de la statuette était normale et n'empêchait en rien, cependant, de tourner les pages du livre, qui étaient de grosse laine noire. Je m'étais empressé de l'acquérir et, en m'éveillant, j'ai regretté de ne pas le trouver près de moi (Béhar, 1988: 238).

Tras este sueño, Breton propondrá la fabricación de los objetos observados en sus aventuras oníricas, los cuales no podían elaborarse atendiendo a las prácticas utilitarias, ni tampoco a concepción estética alguna (Foster, Krauss, Bois, 2006: 250). Estos objetos resultaban ser profundamente enigmáticos para quien los contemplara, puesto que solo respondían a la voluntad onírica de su creador. Así pues, dichos objetos carecían de materia física, ya que se trataba de ideas procedentes de los sueños. Una serie de conceptos que se bosquejaban sobre una hoja de papel a modo de anteproyecto de lo que posteriormente sería la obra de arte en sí. La literatura será el taller donde el escritor surrealista ensayará la representación de sus sueños. En ocasiones, estos cristalizaban en el reino de la vigilia, pero un considerable número de ellos permanecían en la mente de poetas y narradores, latentes en el silencio, esperando manifestarse en cualquier momento de improviso. El texto escrito, por lo tanto, se presentará como el único medio de poder conducir esas ideas hacia el mundo de la realidad.

Los intereses pictóricos de los artistas plásticos son relegados a un segundo lugar por el objeto surrealista. Esta evidencia puede constatarse en la parisina Galerie des Beaux-arts, donde, en 1938, tuvo lugar la Exposition internationale du surréalisme, la cual gozó de la inestimable ayuda escenográfica de Marcel Duchamp. En dicho evento, los artistas surrealistas exponían el resultado de ese proceso de convertir la materia simbólica de sus sueños en objetos físicos. En estos objetos no había lógica alguna, ya que 
las únicas reglas que se seguían eran aquellas que provenían del subconsciente. Un significado que se encontraba sumergido en las oscuras lagunas de su espíritu, donde, solo a través de los sueños, era posible materializar dichos objetos en su forma y sentido. En cierto modo, si estos objetos eran considerados como arte, era debido a la fuerte influencia del mundo onírico sobre la actividad creadora de los surrealistas.

Nada más traspasar el umbral de la Exposition, se encontraba un gran número de bolsas de carbón colgadas del techo. En el suelo, un tapiz de hojas y ramas se extendía por doquier, llegando hasta la orilla de una piscina cuyos bordes estaban cubiertos de hierba y, en una de las esquinas de la sala, se distinguía una inmensa cama sin aparente funcionalidad. En este recinto, había también un pasillo lleno de muñecas y maniquíes a los que se travestía de distintos modos, malversando su apariencia y dando así rienda suelta a la «performatividad $»^{2}$ de su ficticia identidad. Al fondo del pasillo, se encontraba el pintor André Masson (1896-1987) vestido con un traje confeccionado a base de ojos de cristal. Más allá de la performance del artista $^{3}$, se distinguía la cabeza de un maniquí dentro de una caja de mimbre, amordazada con una banda negra y decorada con un pensamiento escrito en papel a la altura de la boca. Breton participó también en la Exposition con un curioso montaje de diversos objetos, cuya composición global terminaba con un tirachinas que proyectaba un caramelo sobre un timbre. Gala Éluard Dalí (1913-1982), por su parte, expuso su célebre caja con dos senos de esponja y un cable en su interior, todo ello instalado sobre unos muelles que lanzaban uno de los falsos pechos sobre una cacerola de harina y el otro sobre un cepillo metálico. Otros artistas, antes y después de la Exposition, también se interesaron por el mundo del objeto surrealista, aunque fue May Ray quien destacaría con mayor fuerza (1890-1976), especialmente debido a su obra Cadeau, la cual consistía en una plancha con puntiagudos clavos soldados en su base.

Sin embargo, fue Salvador Dalí (1904-1989) quien superó a todos ellos en cuanto a lo que se refiere a imaginación creativa. Esto se debe a que el

${ }^{2}$ Entiéndase este término teniendo presente los presupuestos teóricos de Judith Butler, quien, aludiendo a lo que da en llamar la «performatividad del género», indica que los individuos se dividen y se jerarquizan de forma coercitiva en función de reglas sociales, tabúes, prohibiciones y amenazas punitivas que actúan a través de la repetición ritualizada de las normas. Es a partir de todos estos condicionantes que, hombres y mujeres, construyen su propia identidad. En el universo surreal, las identidades se ven alteradas por los sueños, ya que no responden a ninguna reglamentación establecida por orden conocido.

${ }^{3}$ Sírvase la utilización del masculino genérico para aludir tanto a mujeres como a hombres. 
artista catalán, en la entrada de la Exposition, justo en el centro del patio, colocó su obra Taxi Pluvieux, tratándose esta de un coche auténtico conducido por una muñeca, por el que caía gran cantidad de agua, mientras lo recorrían un tropel de caracoles vivos. Otro de los objetos del ex alumno de la Residencia de Estudiantes fue el zapato de una mujer hundido dentro de un vaso de leche, sobre el que colgaba una cuerda con un pequeño marco con otro calzado en su interior, acompañado de un terrón de azúcar que podía disolverse en la leche con solo accionar una palanca. Dalí fue, sin duda, quien más se arriesgó en materializar la realidad onírica de su subconsciente, dado que este partía de la base de que el objeto en sí existía desde que aparecía en su mente, por lo que su cristalización en el universo de la materia era un proceso fácil de realizar. Entre las múltiples propuestas del artista catalán, quedándose muchas en su mente, se encontraba la fabricación de grandes automóviles, tres veces más grandes que los ordinarios, hechos de escayola y ónice, que debían cubrirse con vestidos blancos de mujer, siendo, todos estos, enterrados en sepulturas señaladas por minúsculos relojes de paja. Todo un mundo simbólico que no buscaba interpretación alguna en el terreno de la realidad consciente, sino que su esbozo onírico se reproducía directamente sobre la materia física.

Estos bosquejos conceptuales respondían a la manera que Dalí tenía de comprender el objeto surrealista, el cual, según su propia definición, «représente un minimum de fonctionnement mécanique, basé aux fantômes et aux représentations susceptibles d'être provoquées par la réalisation des actes inconscients» (Gómez, 2004: 99). Sin duda, una explicación algo vaga, aunque puede comprenderse mejor cuando añade que lo que buscaba era el provocar el mayor número de «impactos» posibles sobre el público receptor de la obra. Así, en la producción surrealista, se constata cómo era factible construir objetos móviles lo suficientemente eróticos como para generar emociones sexuales sobre los individuos que los contemplaban, aunque estas llegaran de forma indirecta - piénsese, por ejemplo, en el zapato de mujer de Dalí antes mencionado. Breton, en su ensayo Les vases communicants (1932), aludía a estos anteproyectos, sosteniendo que los objetos surrealistas eran mucho más eficaces que aquellos «systématiquement déterminés» para generar dicha impresión. Para el escritor francés, el efecto de choque desaparecía en el espectador cuando los contenidos eran demasiado explícitos.

El objetivo de todas estas creaciones surrealistas era el de provocar una reacción de sorpresa a partir de la contemplación visual del objeto, el cual poseía ya un uso determinado, pero el artista sugería, e invitaba a 
buscar, otro distinto para brindar nuevas posibilidades funcionales, prolongando así su campo de visión creativa. Con todo, en la literatura, el objeto surrealista tendrá siempre un objetivo concreto, pues su uso, y funcionalidad - sea esta material u onírica一, se manifestará ante el lector como un hecho irrefutable. La base conceptual que conforma el objeto esbozado en la literatura será exactamente la misma que cristalice en la realidad física, pero su simbología tendrá un complemento mucho más descriptivo gracias al texto escrito.

\section{LA TRANSFIGURACIÓN DEL OBJETO EN EL TEXTO SURREALISTA: ARTE Y POLÍTICA}

Ya se ha podido comprobar que los objetos desempeñan un importante rol en el universo surrealista, y no solamente en cuanto a lo que atañe a la pintura o escultura, sino también en lo referente a la creación literaria. Dichos objetos, esbozados dentro del texto escrito, son el prolegómeno físico de los noctívagos sueños de aquellos artistas que encontraron en la realidad diurna el estimulante necesario para su delirio creativo. André Breton, en Les vases communicants, había intentado demostrar, desde un principio, que el mundo real y el de los sueños eran en realidad uno solo. Para el escritor surrealista, no existía ninguna diferencia entre ambas dimensiones. Esto nos llevaba a la negación absoluta de la inteligencia humana tal como tradicionalmente era concebida, dado que esta cortaba el flujo del saber proveniente del inconsciente y, en consecuencia, destruía la susodicha capacidad en sí. Sostenía el autor, además, que todo el mundo era poeta en el momento en que aceptaba ponerse bajo las órdenes de su subconsciente, porque el surrealismo era la puerta de toda manifestación artística. Breton (1963: 3) insistía también en que entonces todavía se vivía en el reino de la lógica, aunque, cada vez con mayor frecuencia, la praxis de los procesos lógicos en la resolución de dilemas cotidianos iba quedándose en un plano secundario. La imaginación, por lo tanto, debía reclamar aquellos derechos que le correspondían por ley.

Años más tarde, en el Manifeste du Surréalisme (1924), Breton reivindicará el valor del sueño, a través del cual podía alcanzarse la realidad absoluta: la surrealidad. El espíritu del ser humano que sueña encuentra el sosiego, y la paz, en todo aquello que le acontece, porque el sueño en sí puede ser aplicado a la resolución de aquellas cuestiones fundamentales en la vida. Esta particular «realidad» únicamente subsiste dentro del espacio onírico y, en ese sentido, el estado de vigilia se presenta como un fenómeno de inter- 
ferencia entre lo real lógico y lo surreal, donde el espíritu del individuo constata la existencia de una extraña tendencia a la desorientación que pauta sus actos y pensamientos. Es entonces cuando invoca, con cierta desesperación de causa, al azar, sin duda el hado más obscuro del destino humano, a quien atribuye todos sus extravíos. Breton concebía estas dos dimensiones del ser humano indisociables la una de la otra, e incluso indispensables para el surrealismo: «je crois à la résolution future de ces deux états, en apparence si contradictoires, que sont le rêve et la réalité, en une sorte de réalité absolue, de surréalité, si l'on peut ainsi dire» (1963: 5). A partir de la importancia otorgada a la influencia de los sueños sobre esa «realidad», no solo de los procedentes del universo onírico, sino también de aquellos originarios del estado de no-vigilia, puede interpretarse el sentido de las situaciones, o los objetos, que en ellas/os se proyecta. En este caso, los descubrimientos de Sigmund Freud (1856-1939) son de suma utilidad para tener un referente metodológico a la hora de dilucidar el sentido de los sueños y la plasmación del objeto surrealista. André Breton, quien estaba familiarizado con los métodos freudianos al haberlos puesto en práctica con distintos enfermos durante la Gran Guerra (1914-1918), se propuso obtener la respuesta más exacta posible al análisis interpretativo del universo onírico: «soit un monologue de débit aussi rapide que possible, sur lequel l'esprit critique du sujet ne fasse porter aucun jugement, qui ne s'embarrasse, par suite, d'aucune réticence, et qui soit aussi exactement que possible la pensée parlée» (1963: 8). De ahí nació la escritura automática, un modo de redactar carente de sentido, sin control racional y cuya «lógica» podía encontrarse en Les champs magnétiques (1919), ensayo escrito por André Breton y Philippe Soupault (1897-1990), el cual es considerado como el origen del movimiento surrealista.

No obstante, aunque Breton examinó las diferentes teorías que se proponían para interpretar el sentido de los sueños, y el de los objetos surrealistas inventados por el subconsciente en este universo onírico, este estaba convencido de que la unidad entre sueño y realidad debía pasar obligatoriamente por una profunda transformación social. Es por esta razón que, más allá de la simbología artística de la revolución surreal, el escritor francés buscó el verdadero destino del ser humano dentro del marco de la realidad social. En aquella época, el PCF fue un importante referente político para el movimiento surrealista, quien, a través de su revolución estética, intentaba regenerar a la sociedad francesa (Gómez, 2004: 47). El objeto surrealista, por lo tanto, será el reflejo de la tensión social entre arte y política, pero también de su buscada comunión en tanto que se entremezclaba con la realidad so- 
cial cotidiana, aunque con las credenciales de obra de arte en sí. Así, Breton, en 1926, pese a no aceptar disciplina alguna por parte del Partido Comunista, organizó a los obreros de la compañía de gas de París, apoyando de este modo al Partido (Browder, 1967: 85). Al año siguiente, junto a Paul Éluard (1895-1952) y Louis Aragon (1897-1982), se afilió al PCF, con el objeto de pasar del plano ideológico a la militancia.

Los surrealistas se encontraban influenciados por la filosofía de Friedrich Hegel (1770-1831), igual que lo estaban los comunistas marxistas, pero sobre todo por la traducción que Lenin (1870-1924) hizo de los principios teóricos del filósofo alemán. Los surrealistas se sorprendían de la superioridad que Hegel había concedido a lo concreto por encima de lo abstracto, declarándose contrarios a tal determinación. Aunque, por otro lado, coincidían en el hecho de que la metafísica no se alcanzaba por pura transcendencia, sino por la conveniente armonización entre el espíritu y la materia (Drew, 1981). Sin embargo, contrariamente a Lenin y a sus adeptos, incluso al propio Marx (1818-1883), los surrealistas estaban dispuestos a impedir el peligro que Hegel dejaba entrever en su obra Esthétique ou philosophie de l'art ${ }^{4}$ (Aestheticam sive philosophiam artis) (1818-1829), no siendo este otro que el de imitar la naturaleza y la fijación establecida de los límites de lo posible. El objeto surrealista se fundamentaba en la estética de la transgresión, es decir, en aquella que se muestra contraria a las reglas establecidas por todo orden natural.

Breton simpatizaba también con León Trotsky (1879-1940), quien, al igual que había hecho el escritor francés con el movimiento Dadá, terminaría por enfrentarse con el Partido Comunista ruso. Trotsky también admiraba la doctrina freudiana, puesto que en su obra Littérature et Révolution (1924) afirmaba que era posible vincular el materialismo con la teoría psicoanalítica, la cual era clave para la interpretación de los objetos del mundo onírico (Trotsky, 2002). Sin duda, el problema político fue esencial para la praxis artística del surrealismo, en cuyo seno la libertad creativa comulgaba con la libertad promulgada por la dogmática comunista.

En 1929, fecha en la que aparecía el Second Manifeste Surréaliste, volvieron a aparecer las diferencias ya existentes entre los miembros del grupo. Breton pidió, entonces, a sus integrantes comprometerse con la «occultation profonde —et- véritable du surréalisme» (1962: 211). Una occultation que

4 Las obras escritas en otros idiomas, por unificar los títulos con la producción de las obras surrealistas escritas en francés, se citan también en dicha lengua. 
proclamaba con enérgica pasión, y cuyo sentido iba más allá del hecho de implicarse más en el movimiento, dado que significaba también concebir el surrealismo como una verdadera forma de vida. Sin embargo, sobre 1930, la popularidad de la corriente artística e ideológica menguó considerablemente, pasando a ser un tema secundario en las revistas de arte (Bridel, 1988: 24). Ante este aparente declive del surrealismo, Breton negó a aquellos escritores que, según los propios surrealistas, habían sido la base inspiradora del movimiento: Arthur Rimbaud (1854-1891), Charles Baudelaire (1821-1867), Edgar Allan Poe (1809-1849) y el Marques de Sade (1740-1814). Además, también se mostró reacio a la presencia de varios de quienes habían sido sus compañeros dentro del círculo surrealista, entre los que figuraban Francis Gérard, seudónimo de Gérard Rosenthal (1903-1992) y Pierre Naville (1904-1993), por haber franqueado la línea divisoria entre el arte y la actividad política; André Masson (1896-1987) y Antonin Artaud (1896-1948), por su «absentéisme social»; o Robert Desnos (1900-1945), por su excesivo narcicismo. La respuesta de todos estos artistas se resumió en un texto titulado Un cadavre (1930), el cual era un panfleto publicitario, que, con el mismo nombre que el escrito en 1924 contra Anatole France (18441924), denunciaba las nuevas sendas que había tomado el movimiento y se mostraba claramente crítico frente a Breton (Adamowicz, 1998: 150). Un cadavre fue un punto de inflexión, no solo en la dirección que tomaría el surrealismo, sino también en el modo de concebir su creación artística y el modo de interpretar la realidad y los objetos que la constituyen.

Pese a esta importante deserción, todavía quedaban otros surrealistas que, como Luis Buñuel (1900-1983) o Salvador Dalí, decidieron unirse a aquellos artistas y escritores que crearon dicha corriente artístico-ideológica: René Crevel (1900-1935), Paul Éluard, Louis Aragon, Benjamin Péret (1899-1959), Max Ernst (1981-1976), Yves Tanguy (1900-1955) y, claro está, André Breton. Sin embargo, a pesar de estas nuevas integraciones en el grupo surrealista, otros miembros se alejaron de este foco originario, siendo la separación más dolorosa la de Louis Aragon. El distanciamiento del poeta y escritor francés influenció al resto de los surrealistas, quienes, a raíz de ello, empezaron a rechazar someterse a la voluntad colectiva del grupo. En 1927, Aragon ingresa en el Partido Comunista Francés (PCF) con el propósito de comprometerse de un modo firme con la lucha política, pero no fue hasta haber viajado por primera vez a la Unión Soviética, en 1932, cuando se convenció de la imperiosa necesidad de seguir, defender y difundir los ideales comunistas. Aragon publica, entonces, un artículo titulado «Front rouge», aparecido en la revista Littérature de la Révolution Mondiale, donde 
soliviantaba a sus lectores, no solo para matar a los dirigentes del régimen capitalista, sino también a aquellos individuos que él denominaba «ours dressés» (osos amaestrados) de la socialdemocracia (Spiteri, LaCoss, 2002: 29; apud: Ibarlucia, 2004b: 75). Debido a este escrito, Aragon fue acusado de incitación al asesinato, corriendo así el riesgo de ser encarcelado por largo tiempo, aunque nunca llegó a ingresar en prisión. Pese al escándalo provocado por este, los surrealistas se hicieron responsables del texto, pero Breton continuó creyendo que su composición era de lo más retrógrada. Tras este incidente, la ruptura entre los dirigentes del movimiento surrealista fue definitiva, provocando que la relación entre el surrealismo y el PCF fuera cada vez más tensa, hasta que, en 1933, Breton, Éluard y Crevel, fueron expulsados del Partido por haberlo criticado con dureza.

En todo este proceso de evolución político-artística, el objeto surrealista se materializa en función de la implicación política de los miembros del grupo, aun sin abandonar en ningún momento su fuerte vínculo con el universo onírico.

\section{ALGUNOS PRECEDENTES LITERARIOS DEL OBJETO SURREALISTA: HOFFMANN Y MAUPASSANT}

Aunque no se corresponda del todo con lo que damos en llamar objeto surrealista, en algunos relatos literarios, especialmente en el género fantástico, se constatan algunos elementos que pueden concebirse como directos referentes a la creación surrealista. Theodor Amadeus Hoffmann (17761822) fue quien inició esta tendencia de incorporar la sorpresa dentro del objeto, siendo un claro ejemplo de ello su cuento «Coppélius», más conocido bajo el título de «L'homme du sable» (Hoffmann, 1953: 207-243). Este texto narra la historia de un joven estudiante llamado Nathanaël, quien, traumatizado por la muerte de su padre, se enamora de una muñeca mecánica llamada Olympia. Dicha autómata había sido creada por Splanzani, un científico algo excéntrico que, para conseguirlo, recurre a la ayuda de un misterioso personaje. Este enigmático individuo, a quien se le da el nombre de «el hombre de arena», Coppélius, es un ser maligno al que Nathanaël - Hoffmann, en realidad - teme desde su infancia, pues cree firmemente que este arranca los ojos de los niños, echándoles arena hasta sangrar, y llevándoselos luego consigo para alimentar a sus hijos; además de ser él el asesino de su progenitor. Los dos científicos venden al inocente estudiante una gafas mágicas que hacen que vea a la muñeca como si de una mujer real se tratase. Hoffmann pronto cae en la trampa al «utilizar» el objeto sin con- 
templaciones y, tras haber declarado su amor a Olympia en el transcurso de un vals, la muñeca enloquece y termina siendo desmembrada a manos del Dr. Coppélius. A raíz de este trauma, el joven decide suicidarse.

En este cuento, pueden apreciarse dos precedentes al objeto surrealista. Por un lado, están las gafas que Spalanzani y Coppélius fabrican con la intención de que Hoffmann pueda pernotar vida en el autómata; mientras que, por otra parte, se encuentra la propia muñeca, la cual es un objeto en sí misma al ser una especie de robot. Sin embargo, existe una diferencia significativa con los objetos surrealistas, ya que estos dos instrumentos poseen una utilidad concreta: la de inspirar el amor en el joven estudiante. La finalidad de ambos objetos es, por lo tanto, la de engañar, estafar, hacer que el individuo que bajo sus efectos se encuentre caiga enamorado contra su voluntad y no la de sorprender a la persona que los descubre.

Esta peculiar relación entre los objetos y el amor, entre aquellos entes que no pueden considerarse humanos y ese sentimiento de pasión irracional, vuelve a aparecer en la obra de Hoffmann. Un claro ejemplo de ello lo tenemos en el cuento «Le Philosophe Angora», donde un gato llamado Mürr dotado de alma humana, como la que se le otorgaba a Olympia, relata la historia de dos enamorados. Ponto, el perro que aparece en la historia, el cual no es tan «culto» como su compañero felino, en un momento de lucidez, piensa que, por muy bien que hablara el gato, este no dejaba de ser un animal como él, por lo que difícilmente podía entender el significado del amor. Pese a ello, Mürr niega el hecho de no ser capaz de discernir las particularidades de dicha manifestación del espíritu humano, demostrándolo con el argumento siguiente: «Peut-être, répondis-je, n'ai-je jamais aimé dans le sens exact que tu attaches à cette expression ; car, d'après ce que j'ai lu, l'amour est une maladie de l'âme, qui nous fait voir les objets tout autres qu'ils ne sont en réalité» (Hoffmann, s.a.: 100). En cierto modo, con estas palabras, el gato Mürr nos ofrece la clave para interpretar el sentido de los objetos surrealistas, la cual no es otra que la de observar con pasión dichos aparejos. Un amor que, en realidad, es el del «amor al arte».

Guy de Maupassant (1850-1893) es otro de los referentes literarios del objeto surrealista. En su cuento «Lui ?», los muebles cobran vida gracias a una especie de sortilegio, abandonando así, en fila india y en plena noche, la mansión en la que se encontraban. En ese mismo instante, el protagonista de la historia manifiesta el pánico que le inspiran los mencionados objetos, los cuales permanecían aún inmóviles apenas unas horas antes (Maupassant, 2006: 56). Como ocurría con Olympia, estos objetos, al habérseles insuflado 
vida, no solo transgredían las leyes físicas del universo, sino también la funcionalidad para la que habían sido creados desde el inicio de su existencia material. Estos muebles, por lo tanto, carecían de toda utilidad, igual que ocurría con los objetos surrealistas, pero en este caso esta circunstancia no era intencionada, sino que se debía al hecho de que se habían convertido en seres vivos.

Maupassant recurre de nuevo a este fenómeno en su cuento «La morte». En este relato corto, el protagonista, tras el entierro de su amada y volver a París después de un largo viaje para digerir su duelo, al verse en el espejo del recibidor, percibe la presencia de su mujer en el objeto. Tantas habían sido las veces que ella se había mirado sobre su superficie, que su alma había quedado metafóricamente atrapada en su interior. De este modo describía esta circunstancia el narrador de la historia al verse frente al gélido objeto, sintiendo, todavía, en lo más profundo de su ser, el insoportable sufrimiento causado por la ausencia de la amada:

Il me sembla que j'aimais cette glace, —je la touchai,_elle était froide! Oh! le souvenir! le souvenir! miroir douloureux, miroir brûlant, miroir vivant, miroir horrible, qui fait souffrir toutes les tortures! Heureux les hommes dont le cœur, comme une glace où glissent et s'effacent les reflets, oublie tout ce qu'il a contenu, tout ce qui a passé devant lui, tout ce qui s'est contemplé, miré, dans son affection, dans son amour! Comme je souffre! (2006: 140).

El espejo es un objeto igualmente cargado de vida, dado que este posee memoria, recuerdos que pertenecieron a quien en otro tiempo le dio uso; salvándose así del indolente olvido ${ }^{5}$ Un objeto en torno al cual se crea un extraño magnetismo que consigue unir a ambos seres en un mismo cuerpo físico, pero también en un único plano espiritual. El espejo simboliza una puerta a la ficción literaria, en el mismo umbral en el que se sitúa el objeto surrealista, en esa dimensión de arte-vida, cuyo sentido se halla en la voluntad del artista. En este espacio imaginario, imposible de definir con la lógica discursiva, se une la utilidad con la sinrazón de ser, cuya fuga hacia la realidad se encuentra en el arte en sí.

\footnotetext{
5 Cabe destacar la importancia del olvido en la producción de Aragon, así como su relación con el objeto surrealista, especialmente en la novela Blanche ou l'oubli (1967). En esta obra, su protagonista, Geoffroy Gaiffier, será visto por Marie-Noire — personificación misma del oscuro olvido- como una máquina creada para reconstituir el pasado, una especie de memoria paralela en constante fabricación de recuerdos nacidos de los sueños, donde el tiempo real se entremezcla con el imaginado en el espacio onírico (Aragon, 1967: 117, 134).
} 


\section{EL AUTOMATISMO PSICOLÓGICO: LOS REGALOS DE MIRABELLE}

Steven Harris (2004) indica que, en Breton, el objeto permanece siempre vinculado al automatismo psicológico y a la metáfora surrealista, pero sin apartarse por ello del collage modernista en el que existe. Un automatismo cuya «lógica» debe buscarse en Les champs magnétiques, texto que Breton escribiría conjuntamente con Soupault, y al que ambos autores dotaron de eminente carácter poético. Esta obra es la primera experiencia surrealista digna de recibir este nombre, pues acontece dentro del laboratorio del lenguaje. Escrito en 1919, según el prólogo del narrador y poeta parisino Alain Jouffroy (1928-), el ensayo responde a la célebre definición que del surrealismo dio André Breton, cinco años antes, en su primer manifiesto: «Automatisme psychique pur par lequel on se propose d'exprimer soit verbalement, soit par écrit, soit de toute autre manière, le fonctionnement réel de la pensée» (Jouffroy, 1967: 8). Los surrealistas, por lo tanto, pretendían explicar el funcionamiento real del pensamiento a través del método de la escritura automática, ya que este conservaba la espontaneidad del arte surrealista.

Aragon, por su parte, en Anicet ou le panorama (1921), representa la imagen de la modernidad ${ }^{6}$, atribuyéndole los rasgos de una misteriosa mujer llamada Mire o Mirabelle ${ }^{7}$ de modo análogo a cómo Breton lo hará con Nadja; aunque Aragon no se limita a plasmar el amor hacia un paradigma de mujer, como ocurre en Nadja (1928), sino que va más allá al intentar abordar todo aquello que la vida posee en su eterna complejidad. Uno de los temas de discusión fue el de la Gran Guerra (1914-1918) y las consecuencias que trajo a la sociedad francesa. Constatamos este hecho cuando Marchesino cuenta a Anicet los únicos amores que Mirabelle había tenido a lo largo de su vida: «On ne lui a connu que deux amants heureux lesquels sont morts assez rapidement pour donner à réfléchir. Le dernier avait gagné ses bonnes grâces en transfigurant pour elle les horreurs de la guerre, aussi trépassa-t-il le jour même que la guerre se termina» (Aragon, 1921: 56). En cierto modo, el conflicto bélico era un modo de llamar la atención de Mire para enmelar sus oídos ansiosos de relatos fuera de lo común — surrealistas en última

\footnotetext{
6 Aragon decía que, en aquel entonces, en el seno del incipiente movimiento surrealista, el mundo no estaba gobernado más que por espíritus que únicamente reflexionaban sobre sí mismos: «C'était l'époque des solutions élégantes, on ne discutait même plus la formule: l'Art pour l'Art, on l'inscrivait tout comme une autre au fronton des édifices publics» (Aragon, 1921: 110).

7 Mirabelle era, en realidad, Madame de B, quien, por otra parte, no tenía nada de extraordinario (Aragon, 1921: 87).
} 
instancia-, pero también carentes de sentido lógico como los versados sobre la tragedia mundial.

La anexión moderna del subconsciente al relato surrealista establece un nuevo parámetro de coordenadas, el cual se convierte en un sistema de referencia clave para la creación de la poética surrealista. Este proceso de devanado literario del pensamiento, de sutil exploración del inconsciente, si tenemos en cuenta el hecho de que los surrealistas estaban especialmente influenciados por las teorías del psicoanálisis freudiano, resalta el carácter experimental de la obra en sí. Así, entre las páginas de Les champs magnétiques, pueden encontrarse sueños que no tienen sentido alguno dentro de nuestra realidad cotidiana, pero que, sin embargo, hacen que su escritura tenga un modelo donde inspirarse: «les grands marais phosphorescents font de jolis rêves et les crocodiles se reprennent la valise faite avec leur peau» (Breton, Soupault, 1967: 42). El mundo salvaje de esta particular jungla, donde los cocodrilos usan su propia piel como si fueran maletas, halla su representación onírica en el marco de la gran ciudad donde lo surreal no solo forma parte del escenario contextual, sino también de los objetos que lo constituyen. La fluidez del pensamiento se entremezcla con las arterias de la urbe, con sus avenidas y largos bulevares, donde puede descubrirse la huidiza luz artificial de los rótulos de neón de los bares; bailes grotescos dentro de casas en ruinas que se prolongan hasta el amanecer (Ibíd.: 16); radiantes estaciones de ferrocarril con sus salas de espera atemperadas por el sonido reiterado del marcado de billetes (Ibíd.: 24); habitaciones de hotel de lasciva luz carmesí, donde el corazón late como una campana fina y pálida por su exposición al sol (Ibíd.: 77); ultramarinos llenos de gente cuyas sonrisas poseen la misma expresión; restaurantes donde la música se esconde bajo los platos (Ibíd.: 51); toda una caleidoscópica variedad de lugares que convertían a Paris en el perfecto lienzo para plasmar todos aquellos vocablos oriundos del subconsciente, que adquirían forma de objeto para hacerse palpables en el dominio de la lógica física.

De nuevo en Anicet, sin abandonar en ningún momento ese singular vínculo con la modernidad, se observa cómo Mirabelle es quien infunde vida al protagonista de la historia, dado que esta se presenta como la esencia misma de la identidad femenina según la interpretación surrealista. Anicet encuentra a Mire en la habitación de un hotel, aunque aparentemente ya se conocían desde hacía mucho, pues éste confiesa que era la única mujer por la que su corazón nunca había dejado de latir (Aragon, 1921: 39). Es probable que, en ese momento, ella no fuera más que la proyección de su propio subconsciente, un sueño escondido en lo más recóndito de su pensamiento 
que emergía para reclamar su espacio físico en el universo de lo real. Un anhelo de vida que, no obstante, es compartido por siete hombres más que compiten por el amor de Mirabelle: el pintor Bleu, cuya identidad es la de Pablo Picasso (1881-1973); los escritores Jean Chipre, el Homme Pauvre ${ }^{8}$, y el profesor Omme, quienes representan a Max Jacob (1876-1944) y Paul Valéry $^{9}$ (1871-1945); el joven dandy Ange Miracle, quien no es otro que Jean Cocteau (1889-1963); André Breton cuyo alter ego es Baptiste Ajamais; Charles Chaplin (1889-1977) es Po; y, finalmente, el elegante desconocido Marchesino - al margen de estos siete pretendientes-, se encuentra Harry James, personaje inspirado en Jacques Vaché (1895-1919), el amigo de Breton que, en enero de 1919, murió por sobredosis de opio, y quien, según el escritor normando, era un «véritable homme moderne» (Aragon, 1921: 94). Todos estos aspirantes forman parte de una asociación anónima cuyo objetivo era el de procurar el advenimiento de un nuevo orden de concebir la realidad, donde no se diera por hecho el nombre - ni el uso- de todo aquello que la envuelve: «L'histoire des récentes écoles littéraires nous a appris à nous défier des étiquettes. Les classiques n'avaient pas de nom et nous sommes les classiques de demain» (Aragon, 1921: 58). La sociedad formada por estos siete ${ }^{10}$ individuos resulta ser una especie de compañía secreta que conspira en pro de la consolidación de la modernidad, valiéndose para ello de la beldad de Mirabelle, quien, en verdad, simboliza la cualidad estética de la belleza en sí (Aragon, 1921: 21).

Antes de que Anicet formara parte de esa asociación, en el cuarto donde conoce a Mirabelle, tras una inesperada proposición sexual por parte de ella que el protagonista no se atreve a aceptar, los siete miembros del grupo irrumpen en la habitación, accediendo a ella a través de distintas puertas que permanecían ocultas en la sala. Aragon les otorga el nombre de «dorophores», neologismo que en francés significa «porteurs de présents», siendo estos, por lo tanto, portadores de regalos que ofrecen a Mire desde un seguro anonimato, ya que todos ellos esconden el rostro tras una máscara (Narjoux, 2001: 121). Cada uno de estos presentes son fragmentos oníricos del sub-

8 Jean Chipre comenta que la riqueza en el arte se denominaba «mauvais goût», reivindicando, así, la pobreza como único medio de imaginación y de creatividad (Aragon, 1921: 67). 1996: 5).

También se lo ha identificado con el poeta y dramaturgo Alfred Jarry (1873-1907) (Gindine,

10 Cécile Narjoux (2001: 121) nos recuerda que ese siete simboliza «un cycle complet», la «perfection dynamique» y la «vie éternelle». En este sentido, la comunión de estos siete artistas se concibe como la más pura representación del arte en sí, la eterna capacidad de entendimiento hacia la realidad palpable y el único criterio válido por el que podía aprehenderse lo eterno. 
consciente del propio autor, los cuales poseen una simbología determinada y traen consigo una reacción específica por parte de Mirabelle al recibirlos. A continuación, se expone la relación de estos objetos con su interpretación simbólica y la consecuente respuesta conductual de su destinataria:

\section{Objeto 1. Una bola de cristal argentado}

Nombre del «dorophore»: Ange Miracle (Jean Cocteau).

Características: Este objeto es recogido por el primer enmascarado, Ange Miracle, en los alrededores de un parque de Paris (Aragon, 1921: 45). Se trata de un globo dentro del cual es posible contemplar el universo, lo que resulta ser muy cómodo para establecer sistemas o efectuar cálculos. Cuando Mirabelle lo observa, percibe su simplicidad, hermosamente teórica y realzada por ciertos destellos de gracia. Así, Mirabelle, muestra un modo especial de concebir la vida, cómoda y reconfortante, ideal para sobrellevar los días de tristeza, el cual le permite introducir orden y razón a la concepción de los fenómenos cósmicos.

Interpretación simbólica: La bola de cristal representa el universo, aunque en su argentado abismo, no se percibe su complejidad, sino que muestra una visión amable y simple del cosmos. La maleabilidad del objeto, y su aparente sencillez, genera la impresión de que el control del universo está al alcance de cualquiera. Con la esfera en sus manos, Mirabelle ostenta el poder de hacer todo aquello que desee, desde resolver los misterios del cosmos hasta jugar con ella como si de una canica se tratase.

Reacción de Mirabelle: Empieza a lanzar la bola contra una de las paredes de la habitación, sin preocuparse de dañarla. Mire concibe el universo, y todos los secretos que en él se encierran, como algo lúdico, trivial y sin importancia.

\section{Objeto 2. Un polígono de tafetán, cuyos colores se alternaban entre rosa y gris}

Nombre del «dorophore»: Baptiste Ajamais (André Breton).

Características: Robado por este segundo enmascarado de una tienda de Novedades, este polígono de tafetán tornasolado adquiere una tonalidad rosa o gris en función de la perspectiva desde la que se lo observe, alegrando o entristeciendo, a su vez, a todo quien deseara contemplarlo (Ibíd.: 47). 
Interpretación simbólica: La eterna dualidad emocional de la tristeza y la alegría.

Reacción de Mirabelle: Mirabelle, colocando sus brazos en forma de elipse, sitúa el primer regalo sobre el tafetán, dejando entonces este de brillar y sin posibilidad alguna de distinguir su dualidad cromática. El universo se encuentra, por lo tanto, bajo la eterna influencia generada por la alegría de vivir y la angustia de la existencia en sí.

\section{Objeto 3. Una mandarina envuelta con papel transparente con inscripciones rojas}

\section{Nombre del «dorophore»: Po (Charles Chaplin).}

Características: La mandarina había sido robada accidentalmente a una vendedora de un teatro, suponiendo ser, en cualquier caso, una acción de lo más acertada para ofrendarla a Mire, ya que esta fruta era la más sabrosa que jamás pudiera probarse (Idem).

Interpretación simbólica: El sol en sí mismo, la luz de la lógica, todo aquello que establece un orden en el mundo diurno, pero construido éste a partir de las consignas del universo onírico.

Reacción de Mirabelle: Este tercer enmascarado ofrece a Mirabelle el fruto para que lo muerda; sin embargo, ésta empieza a jugar con la mandarina balanceándola de izquierda a derecha como si de una flor se tratase (Aragon, 1921: 47-48). Mirabelle juega con la razón, dando preferencia al mundo de los sueños donde la locura y el subconsciente son huéspedes de lujo.

\section{Objeto 4. Una hoja de papel cubierta de cifras}

Nombre del «dorophore»: Marchesino.

Características: Para el cuarto pretendiente, este regalo podía ser una espantosa arma de destrucción, capaz de provocar una nueva guerra mundial si Mirabelle llegaba a conocer su funcionamiento. Afortunadamente, ella nunca podrá descifrar el criptograma de este documento diplomático que el italiano había robado del Ministère des Affaires Étrangères (Aragon, 1921: 49).

Interpretación simbólica: El mundo de la ciencia, y especialmente el de las matemáticas con las que es posible entender la lógica del universo. 
Reacción de Mirabelle: Aragon señala que, en vista de la actitud que Mire había tenido con los otros objetos, pudiera pensarse que esta iba a quemar la hoja en cuestión, o bien tirarla por el suelo, pero sorprendentemente lo que hace es doblarla con cuidado para guardársela en uno de los bolsillos de su blusa (Idem). Mirabelle es sabedora del poder de la razón sobre el mundo de los sueños, por lo que decide guardar el criptograma con la esperanza de poderlo descifrar algún día y poder así conceder más poder a la realidad onírica.

\section{Objeto 5. La medida Ohm}

Nombre del «dorophore»: Paul Valéry / Alfred Jarry (Omme).

Características: Omme, el quinto enmascarado, regala la medida Ohm a Mire, tras haberla robado del Institut des Arts et Métiers. Omme confiesa que no conoce ningún objeto que se rija por el principio de resistencia física, siendo, por lo tanto, la medida que le brinda a Mire la base de toda idea de conocimiento. En este sentido, la física permite al ser humano afirmar que el principio de resistencia implica las nociones de longitud, de sección y de resistividad, lo que supone que para poder evaluar la resistencia de cualquier conductor es necesario conocer su coeficiente de naturaleza o resistividad (Aragon, 1921: 50-51).

Interpretación simbólica: La medida Ohm se concibe como el origen de las ideas puras de toda filosofía, sin ningún tipo de filtración que enturbie el sentido y significado de éstas.

Reacción de Mirabelle: Mirabelle se limita a observar el objeto, pero únicamente durante el tiempo que ella considera necesario.

\section{Objeto 6. La gran señal de bifurcación de la vía de ferrocarril de $P^{*}$ a $M^{*}$ y la de Pontarlier a $N^{*}$}

Nombre del «dorophore»: Bleu (Pablo Picasso).

Características: El sexto pretendiente, «le peintre de paradis», había aprovechado un momento de distracción del guardabarrera para robar la señal de bifurcación, causando, en consecuencia, la colisión del expreso de las 24:30 con el rápido de la 0:29 (Aragon, 1921: 51). 
Interpretación simbólica: Tras la ciencia, la razón, la lógica y la filosofía, llega el turno al infortunio, dado que, al no estar dicha señalización, se produce un terrible accidente de trenes.

Reacción de Mirabelle: Lo cierto es que no se aprecia ninguna reacción. Podemos imaginar, empero, que Mirabelle es ajena al mal del prójimo, y no solo del de quien la agasaja, sino del de todo el género humano, ya que su único interés es ella misma.

\section{Objeto 7. Una antigua fotografía de la actriz Isabelle $R^{*}$ de la que estaba enamorado}

Nombre del «dorophore»: Jean Chipre (Max Jacob).

Características: Para conseguir este objeto, Jean Chipre había asesinado a un amigo suyo, un poeta sin talento con el que desayunaba cada mañana, quien, tiempo atrás, encontró la foto por casualidad sobre el asfalto. Esta imagen era un regalo que una desconocida Isabelle hizo a un joven que, poco después, descuidadamente la perdió en un bulevar. El mal poeta se enamoró tanto del rostro de la joven artista, cuyo genio residía en una sorprendente maestría para tocar el piano, que Chipre tuvo que matarlo para que dejara de mirar la vieja foto amarillenta.

Interpretación simbólica: La fotografía es la memoria, la esperanza y el fin del olvido.

Reacción de Mirabelle: Tampoco se aprecia interés alguno por parte de Mirabelle, ya que, para ella, la esperanza y el recuerdo no tienen razón de ser, ni siquiera en lo atinente al amor o a la amistad.

En realidad, todos estos objetos deben ser concebidos como diferentes piezas de un mismo cuerpo. Un objeto único cuyo proceso de construcción simbólica puede apreciarse a medida que van apareciendo cada una de sus partes, siendo su conglomerado la propia mujer a la que se le brindan todos estos presentes. De este modo, la ceremoniosa mise en scène de los siete enmascarados, se entiende como un ritual ejecutado para la consagración de la figura de Mirabelle. Una devoción que continua procesándose incluso tras saberse que esta es igual de mortal que cualquier otra mujer, sin tener, por lo tanto, ningún trazo de divinidad. Con todo, para el grupo de «dorophores», a los que pronto se une Anicet, el único universo existente es el del amor por esa mujer idealizada hasta la sinrazón. 


\section{EL ESPEJO MÁGICO DE ELSA EN EL POEMA-OBJETO}

En lo atinente a la obra de los surrealistas, especialmente por lo que respecta a su producción literaria, el fenómeno del poema-objeto adquiere una especial relevancia en ese proceso de creación artística. El objeto surrealista puede permeabilizarse en la poesía del texto escrito, transformando el conjunto de sus versos en un objeto psíquico, sin abandonar por ello su armónica relación con el subconsciente del artista. Breton define el poema-objeto como «une composition qui tend a combiner les ressources de la poésie et de la plastique en spéculent sur leur pouvoir d'exaltation réciproque» (Durozoi, 1997: 520). El poema-objeto, por lo tanto, es una criatura anfibia que vive entre dos medios: el signo y la imagen, el arte visual y el arte verbal, siendo tan dependiente de un elemento como del otro. Un poema-objeto se observa, pero al mismo tiempo se lee. Los ritmos son las reglas que fijan las bases para la cristalización de los versos que conforman el poema en la estructura psíquica del poema-objeto, el cual se expone dentro del subconsciente del espíritu creador.

Aragon insiste en la importancia de la creatividad en la rima de la composición poética, puesto que, según el autor surrealista, son las experiencias de los poetas quienes alientan sus almas para expresar sus miedos, emociones y deseos, pero sobre todo para dar forma al amor que estos puedan sentir por un objeto, o sujeto, determinado. En este sentido, la obra titulada Crève-cour (1946) es una clara prueba de ello, dado que el texto en sí es una declaración de amor de Aragon a su mujer, Elsa Triolet. Este poema no será el único que el escritor francés dedicará a su esposa, ya que habrá otros que le servirán igualmente de base para demostrarle sus sentimientos, los cuales, a su vez, también le valdrán de ejercicio de creación poética. Así, Le Fou d'Elsa, compuesto en 1963 por un Aragon ya entrado en años, es uno de los poemas más conocidos en el que el autor canta de nuevo su pasión por Elsa, a la vez que relata la conquista de Granada, en 1492, a manos de los Cristianos.

En este largo poema, se cuentan los verdaderos motivos de la expulsión de los moriscos de España, los cuales han permanecido ocultos a lo largo de los siglos y cuya simbología es mucho más relevante de lo que pudiera creerse. Para ello, y valiéndose de un aedo urbano, una especie de flâneur atemporal llamado Medjnoûn, el autor intenta indagar en el origen del Mal. Para este personaje, los siglos pasan en vano, las sociedades se suceden, igual que los dioses y las filosofías, pero la epidemia del Mal siempre continúa presente: «la peste ne change que de costume, et la charogne à son aise 
étale au grand jour son mufle maquillé» (Aragon, 1963: 54). Medjnoûn reflexiona también sobre el doble problema del tiempo y del devenir del ser humano, cuya única respuesta se encuentra en la Mujer:

\section{L'avenir de l'homme est la femme \\ Elle est la couleur de son âme \\ Elle est sa rumeur et son bruit \\ Et sans elle il n'est qu'un blasphème \\ Il n'est qu'un noyau sans le bruit \\ Sa bouche souffle un vent sauvage \\ Sa vie appartient aux ravages \\ Et sa propre main le détruit (Aragon, 1963: 166).}

Tras haber llegado a esa conclusión, el poeta toma el nombre de Elsa para dirigirle todos sus versos a fin de convertirla en su canto y oración, ya que el futuro de la humanidad depende de la evolución de su amor por ella: «Et pour la première fois ici, les apocryphes du Medjnoûn exceptés, dans le poème emploi s'est trouvé fait du temps futur, ainsi par un étrange jeu de scène entendant marquer qu'il n'est que d'Elsa, que d'Elsa l'avenir, le devenir que d'elle» (1963: 188). Por medio del cantor musulmán, Aragon (1963: 98) añade que las rimas del poema poseen esa maravillosa disparidad existente entre los sexos, la cual otorga siempre a la mujer la ventaja de tener la última palabra. Esto viene a ratificar que el destino se halla en manos de esta, pues la voz de todo fin tiene siempre tono de mujer.

Medjnoûn, además, contempla su alrededor con la lógica de los locos, que, en realidad, no dista mucho de la del resto del mundo, siendo la única diferencia constatable el hecho de que su visión se encuentra condicionada por la irracional cromática de la demencia (1963: 336). Aragon está loco por Elsa, pero por una Elsa que no pertenece al tiempo del poema, sino a otro siglo contemporáneo a su realidad de vida y, por lo tanto, atemporal a la ficción relatada. Esta evidencia se confirma cuando el mensajero Moûssâ pide a Kéis' Abd al-Ozza, el sirviente d'al-Ozza, transportar a su época a aquella a la que se dedica el poema, respondiendo este que no existe ningún poder humano suficientemente poderoso como para invocar a una criatura oriunda de un período situado a cuatrocientos cincuenta años más allá de su presente (1963: 215). En cualquier caso, aunque Elsa no sea todavía real, el solo hecho de que estos estén al corriente de su futura existencia, ya de por sí transformaba la propia realidad en una especie de punto de partida en el proceso de cristalización de ese ser. 
Aragon, no obstante, nos ofrece la posibilidad de viajar en el tiempo a través de un espejo mágico ${ }^{11}$, cuya imagen consiste en una retrospectiva, más allá de las coordenadas psíquicas, donde se podrá encontrar a Elsa en un futuro hipotético, suponiendo ser éste el del presente del autor. Este espejo, además, se encuentra construido con las mismas hilvanadas palabras con las que se compone la poesía. Zaïd, el servidor de Medjnoûn, rápido y silencioso, describe todas las singularidades de este espejo: «Il y a des miroirs d'eau, de ciel (ou mirages)... mais sont les gens trop simples pour entendre qu'il y a miroirs de mots (ou images). C'est pourquoi leur est mystère la poésie où parfois je semble parler d'autre chose il n'est image qui ne serve à montrer Elsa, il n'est image que d'Elsa» (1963: 73). En estas líneas, puede constatarse que no todo el mundo es capaz de mirar dentro de ese espejo. Para conseguirlo, es necesario estar dotado de cierta competencia de observación, una especie de flânerie ante el texto escrito que nos permita contemplar libremente todo aquello que reside en su interior, sin estar sujetos a ningún código conductual predeterminado. Son los ojos del subconsciente, por lo tanto, aquellos que nos abren las puertas del entendimiento al dejarnos ver más allá de lo que encierra la superficie reflectante de dicho utensilio. Asimismo, la lógica onírica ${ }^{12}$ que acompaña al objeto, nos facilita la tarea de comprender el reflejo de las imágenes que éste restituye en el dominio de la razón. El espejo de Elsa nos ofrece, pues, las claves ideológicas para abordar el poema-objeto, dado que sobre su cuerpo reposan las pautas para entender el significado del texto surrealista en sí.

\section{UNA CONCLUSIÓN CON UN GUANTE AZUL CIELO DE BRONCE}

Tras el análisis aquí realizado, se ha podido constatar que el objeto posee una importante significación en la literatura francesa surrealista. Además, vemos cómo dicho objeto puede ser también entendido como un esbozo gráfico de la obra psíquica, la cual toma forma en la obra literaria. Los poemas-objeto son un elemento recurrente en la creación surrealista, especialmente en la de André Breton. Contrariamente a lo que supone la escritu-

11 En Le Fou d'Elsa, podrán encontrarse otros objetos mágicos, entre ellos el de una alfombra voladora, que únicamente podía ser montada por quien estuviera enamorado (Aragon, 1963: 358).

12 Este vínculo con el universo onírico se encuentra en el poema titulado «Miroir», donde pueden leerse los siguientes versos: «Au cœur du paradis physique / Ne voit plus rien quand tu t'en vas / Dans son profond sommeil rêve à / Toi seule aveugle à toute chose / Aux mimosas comme à la rose / Insensible à qui le grisa / Et n'est plus miroir que d'Elsa» (Aragon, 1963: 72). 
ra automática, en Breton, aunque también en Aragon, la rima estructura de un modo muy original la fisonomía del lenguaje. Con todo, debe subrayarse que la escritura automática conforma realidades paralelas, donde, a través de la alquimia de la libertad, esa misma a la que se recurre para la composición del verso libre, es posible transportar los objetos oníricos a un espacio de existencia lógica.

En Les champs magnétiques, puede observarse que este proceso de creación se realiza en las manufacturas del subconsciente, donde los sueños se manifiestan a través de la escritura automática. Con esta técnica, se accede a un universo que la imaginación transforma con vistas a crear un nuevo modo de expresión artística. Valiéndose de esa forma de aprehender y plasmar la íntima realidad de cada ser, el escritor surrealista desempeña el papel de un alquimista que transforma la realidad banal en ficción poética: «chimie mentale de nos projets, vous êtes plus forte que ces cris d'agonie et que les voix enrouées des usines» (Breton, Soupault, 1967: 15). Es entonces cuando se señala que los accidentes laborales ocurridos en las fábricas son más hermosos que los «mariages de raison», dado que es en el interior de los espacios creados en la urbe de la imaginación donde se construye la verdadera realidad. Las manufacturas son como dormitorios comunes donde las máquinas sueñan a toda velocidad, como la escritura automática cuando se escribe rápidamente, sin control de la razón, sin preocupaciones estéticas o morales, sin prestar atención a la coherencia gramatical o tener respeto por el vocabulario utilizado. El individuo, artista o no, escritor o lector, se percibe ante un universo onírico situado más allá de todo lo que abarca la realidad, siendo en el marco de la escritura donde el objeto surrealista formula su deseo de hacerse real, bien a través de su cristalización en el plano físico o en el interior del poema-objeto. He ahí por lo que el objeto surrealista se aparta de toda subjetividad y apuesta por un paradigma de orden onírico general, en respuesta a la difundida creencia burguesa del origen subjetivo de todo arte (Foster, Krauss, Bois, 2006: 250). El objeto surrealista se encuadra, pues, dentro de una dimensión limítrofe entre el plano de lo real y el de lo psíquico, estando constituido por elementos oriundos de ambos espacios.

Al margen de la singularidad de los objetos abordados en este estudio, aunque no se haya mencionado, puede que el más representativo del surrealismo francés sea el guante azul cielo de Nadja. Ignoramos si este es real o no, ni tampoco se le conoce utilidad alguna, puesto que es de bronce, por lo que su uso queda a manos de quien sea capaz de soñarle uno determinado. Los objetos guardan siempre la impronta de quienes los poseyeron, aunque 
en este caso no se sabe nada de su propietaria ${ }^{13}$, porque ésta aparece misteriosamente de improvisto. André Breton describe la fascinación por Nadja y el objeto que la representa del siguiente modo: «Je ne sais ce qu'alors il put y avoir pour moi de redoutablement, de merveilleusement décisif dans la pensée de ce gant quittant pour toujours cette main» (Breton, 1998: 57-59). Pese a su sugestión, la particularidad de este guante reside en el hecho de que nunca será de nuevo aprovechado por su dueña, bien porque al estar hecho de bronce es demasiado pesado o porque su uso rompe la lógica del objeto en sí. Ninguna utilidad coherente puede atribuírsele, sirviendo únicamente para imaginar la mano para la que había sido diseñado, la cual no será otra que la de Nadja. La incongruencia del objeto en sí y su forzada asociación con su uso lógico, nos permite establecer un parangón con la propia mujer, siendo esa mano conjeturada la representación al completo del ente femenino: «La main de feu, c'est à ton sujet, tu sais, c'est toi» (1998: 99). Guantes y manos son una constante en Nadja, dado que entre estos elementos existe un estrecho vínculo con la locura, y más si se tiene en cuenta que es a través de ese estado de alineación que se nos permite acceder al proceso de materialización del objeto, esbozado dentro de la literatura, al plano de la realidad (Schrader, 1990: 1.305). Sin embargo, si bien Breton sabe distinguir entre ese inestable estado de enajenación mental y el de no-folie, aunque decantándose siempre por el primero, Nadja concede a la realidad el exclusivo valor del sueño. Para esta musa del surrealismo, lo onírico ocupa ambas dimensiones de la realidad humana, la física y la psíquica, despertando entre los surrealistas un sentimiento de manifiesta simpatía, ya que su forma de ver el mundo era la misma que la expuesta en el Manifeste du surréalisme. En este sentido, si el surrealismo halla su representación en Nadja, siendo esta una extrapolación del guante de bronce del que hizo uso en su día, el objeto surrealista puede entenderse como la cristalización del propio movimiento artístico sobre el plano físico de la realidad o sobre el universo del texto escrito.

\section{REFERENCIAS BIBLIOGRÁFICAS}

ADAMOWICZ, E. (1998). Surrealist collage in text and image: dissecting the exquisite corpse. Cambridge: Cambridge University Press.

${ }^{13}$ Hoy en día se sabe que el guante perteneció a Lise Meyer, una mujer con quien André Breton tuvo una relación amorosa (Vielwahr, 1998: 274). 
ARAGON, L. (1921). Anicet ou le panorama. Paris: Éditions de la Nouvelle Revue Française.

- (1946). Le Crève-cœur. Paris: Gallimard (Edición primera de 1941).

- (1956). Le roman inachevé. Paris: Gallimard.

- (1963). Le Fou d'Elsa. Paris: Gallimard.

- (1967). Blanche ou l'oubli. Paris: Gallimard.

BALL, E. y KNAFO, R. (1990). «Le dossier R. Mutt». Les Cahiers 33, 7475; cit. pos.: JANG, Y-G. (2001). L'objet duchampien. Paris: L'Harmattan, 46.

BÉHARD, H. (con la colaboración de M. BARBÉ y R. FOURNIER) (1988). Les pensées d'André Breton. Lausanne: L'Âge d'Homme.

BRETON, A. (1927). Introduction au discours sur le peu de réalité. Paris: Gallimard.

- (1998). Nadja. Paris: Gallimard (Edición primera de 1928).

- (1962). Second Manifeste Surréaliste. Paris: Pauvert (Edición primera de 1929).

- (1963). Manifeste du surréalisme. Paris: Gallimard (Edición primera de 1924) (También en inventin.lautre.net/livres/Manifeste-du-surrealisme-1924.pdf).

- (1996). Les vases communicants. Paris: Gallimard (Edición primera de 1932).

BRETON, A. y SOUPAULT, P. (1967). Les champs magnétiques. Paris: Gallimard (Edición primera de 1920).

BRIDEL, Y. (1988). Miroirs du Surréalisme. Lausanne: L'Âge d'Homme.

BROWDER, C. (1967). André Breton: arbiter of surrealism. Genève: Librairie Droz.

DREW EGBERT, D. (1981). El arte y la izquierda en Europa. Barcelona: Gustavo Gili.

DUROZOI, G. (dir.) (1997). Diccionario Akal de arte del siglo xx. Madrid: Akal.

FOSTER, H.; KRAUSS, R. E. y BOIS, Y.-A. (2006). Arte desde 1900: modernidad, antimodernidad, posmodernidad. Madrid: Akal.

GINDINE, Y. (1966). Aragon, prosateur surrealiste. Genève: Droz.

GÓMEZ MORENO, P. P. (2004). El Surrealismo: el pensamiento del objeto y la construcción de mundo. Bogotá: Universidad Distrital Francisco José de Caldas-ASAB. 
HARRIS, S. (2004). Surrealist Art and Thought in the 1930s: Art, Politics, and the Psyche. Cambridge: Cambridge University Press.

HOFFMANN, E. T. A. (s. a.). Contes d'Hoffmann. Bruxelles: Éditions de la Toison d'Or.

- (1953). «L'homme du sable». En Contes fantastiques, 21, 207-243. Paris: Éditions de la Bibliothèque Mondiale.

IBARLUCÍA, R. (2004a). «Estudio preliminar: Louis Aragon y el otro manifiesto del Surrealismo». En Una ola de sueños, L. Aragon, 9-48. Buenos Aires: Biblos.

- (2004b). «Notas». En Una ola de sueños, L. Aragon, 73-114. Buenos Aires: Biblos.

JOUFFROY, A. (1967). «Préface». En Les champs magnétiques, A. Breton y P. Soupault, 7-8. Paris: Gallimard.

MAUPASSANT, Guy de (2006). Le Horla et autres contes fantastiques. Paris: Hachette.

NARJOUX, C. (2001). Le mythe ou la représentation de l'autre dans l'œuvre romanesque d'Aragon. Paris: L'Harmattan.

SCHRADER, L. (1990). «Octavio Paz y el surrealismo francés (Sobre Noche en claro)». En «Sieh den Fluss der Sterne Stromen». Hispanoamerikanische Lyrik der Gegenwart. Interpretationen, Gisela Beutler (ed.), 1.305. Darmstadt, Wiss: Buchges.

SPITERI, R. y LACOSS, D. (eds.) (2002). Surrealism, politics and culture. Hants: Ashgate.

TROTSKI, L. (2002). «La cultura proletaria y el arte proletario». En Literatura y Revolución, L. Trotski. Marxists Internet Archive. Enlace: http:// www.marxists.org/espanol/trotsky/1920s/literatura/06.htm (Edición primera de 1921).

VIELWAHR, A. (1998). S'affranchir des contradictions. André Breton de 1925 à 1930. Paris: L'Harmattan.

Recibido el 12 de junio de 2013.

Aceptado el 19 de septiembre de 2013. 